\title{
АНАЛІЗ ВЛАСТИВОСТЕЙ, ХАРАКТЕРИСТИК ТА РЕЗУЛЬТАТІВ ЗАСТОСУВАННЯ НОВІТНІХ ДЕТЕКТОРІВ ДЛЯ ВИЗНАЧЕННЯ ОСОБЛИВИХ ТОЧОК ЗОБРАЖЕННЯ
}

\begin{abstract}
Вирішується задача інваріантного розпізнавання візуальних об'єктів з використанням структурних методів на основі описів у вигляді множини особливих точок зображення. Проведено аналіз характеристик ma засобів програмного моделювання сучасних методів ORB та BRISK для визначення особливих точок. Запропоновано метод бінарного аналізу для формування центрів класів та подальшої класифікації. Проведено програмне моделювання методу у порівнянні з мережею Кохонена, отримано підтвердження результативності розробленого методу для прикладної бази зображень.
\end{abstract}

Ключові слова: комп'ютерний зір, структурне розпізнавання, особливі точки зображення, методи ORB, BRISK, метод бінарного аналізу, мережа Кохонена, база зображень, програмне моделювання, результативність класифікації.

\section{Вступ}

На цей час у комп’ютерному зорі набули популярності та практичного застосування ряд методів розпізнавання візуальних об'єктів, що засновані на локальних прикметах зображення. Такі методи базуються на визначенні множини особливих точок (OT) та їх описові у вигляді числового чи бінарного вектора - дескриптора, що відображає вміст множини локальних околиць ОТ зображення [1-5]. Значення дескриптора, як правило, інваріантне стосовно групи геометричних перетворень об'єктів на зображенні (зміщення, поворот, масштабування), а кількість утворених дескрипторів, що формують опис, повинна бути достатньою для прийняття результативного рішення відносно розрізнення розпізнаваних об' єктів [1-5].

Можливості сучасних програмних бібліотек комп'ютерного зору, наприклад, Open CV, забезпечують вирішення ряду важливих практичних задач: аналіз вмісту зображень, пошук та розпізнавання заданих об'єктів, виявлення тексту, відстежування рухів об'єктів, виявлення спільних елементів на порівнюваних зображеннях, реалізація методів навчання для баз відеоданих тощо.

Етап розпізнавання при застосуванні таких методів полягає в обчисленні міри релевантності між описами об'єкта та еталона, що задані у вигляді множин дескрипторів. Такий підхід дає можливість комп'ютерній програмі працювати із візуальними образами подібно людині, зір якої теж грунтується на локальних прикметах зображення. Зважаючи, що основу підходу складають синтезовані описи, виникає нагальна необхідність провести порівняльний аналіз можливостей, властивостей та характеристик детекторів для виявлення ОТ та обчислення їх дескрипторів.
Історично раніше розроблено детектори SIFT (Scale Invariant Feature Transform) [8] и SURF (Speeded Up Robust Features) [9]. Вони дають можливість сформувати як множину координат ОТ, так i визначити їх дескриптори. Метод SURF при цьому набув порівняльно переважної популярності із-за поглибленого розроблення та забезпечує суттєво більшу швидкодію оброблення даних в процесі розпізнавання [3]. Однак, тривають цілеспрямовані спроби створення більш простих способів детектування ОТ, обчислення та порівняння дескрипторів, що забезпечують як достатній рівень інваріантності до спотворень, так і перевагу в швидкодії оброблення.

Метою роботи є вивчення властивостей та оцінювання ефективності сучасних детекторів ORB, BRISK для визначення особливих точок зображення при застосуванні їх у методах інваріантного розпізнавання візуальних об'єктів.

Задачами дослідження є розроблення методу та аналіз вибору параметрів та оцінювання характеристик детекторів особливих точок за критерієм результативності класифікації чи якості кластеризації ознак у прикладній базі еталонів.

\section{Методи ORB та BRISK}

У роботі [1] запропоновано новітній метод ORB (Oriented FAST and Rotated BRIEF), який є модифікованою комбінацією методу FAST [4] для виявлення ОТ та визначенням дескриптора у вигляді бінарного рядка по методу BRIEF (Binary Robust Independent Elementary Features) [5]. Метод FAST (Features from Accelerated Test) - один 3 найбільш поширених на практиці детекторів ОТ, визначається тим, що будує прості дерева рішень для класифікації пікселів на ОТ та решту.

На першому етапі для детектування ОТ будується масштабна гаусова піраміда зображення. По- 
тім на кожному масштабному рівні визначаються екстремуми яскравості. Для цього застосовується алгоритм FAST, згідно з яким для кожної точки зображення формується коло деякого радіуса і підраховується число суміжних пікселів, що лежать на ньому і мають значення менше або більше яскравості іï центру. Якщо таких точок знайдеться більше 75\% від їх можливої кількості, то центр кола вважається кандидатом на роль ОТ.

Метод ORB використовує модифікацію FAST-9 (параметр радіусу аналізованого кола 3 пікселів дорівнює 9) для виявлення потенційних ключових точок, далі уточнює їх на підставі детектору кутів Harris та обчислює орієнтацію і дескриптори ОТ 3 використанням BRIEF. Для цього при поточному масштабі формується область і визначається їі центр маси. Орієнтацію ОТ задає вектор, що направлений від координат ОТ до центру маси. Бінарний вектор дескриптора обчислюється шляхом порівняння набору яскравості пар точок всередині квадратного вікна, що центроване відносно координат ОТ та узгоджено з їі орієнтацією. У квадратному вікні по заданому правилу вибирається набір пар точок, значення яскравості в яких порівнюються між собою. Якщо яскравість першої точки вища, то до відповідного елементу дескриптора записується 1 , інакше записується $0[1,6]$.

Зміст алгоритму ORB показує, що він менш вимогливий до обчислювальних ресурсів у порівнянні 3 іншими алгоритмами. Виграш у швидкості обчислень пояснюється простою процедурою побудови дескрипторів. ORB дає за результатами тестування помітний виграш у швидкодії при порівняльній або кращій точності, ніж SIFT та SURF [6].

У роботі [2] представлено метод BRISK (Binary Robust Invariant Scalable Keypoints), що є розвиненням SURF у плані подальшого удосконалення складових FAST та BRIEF. У цьому методі порівняно $з$ ORB надають різні альтернативи форм маски для виявлення ключових точок. Використовується маска 9-16, яка для виконання FAST критерію аналізує 9 послідовних пікселів у 16-піксельному колі з метою, щоб вони були достатньо яскравішими або темнішими від центру. Для різноманіття масштабів застосовано також інші маски.

Враховуючи розташування ключових точок та відповідні значення масштабу, дескриптор BRISK складає дескриптор - двійковий рядок шляхом об'єднання результатів порівняльних тестів яскравості. Ідентифікується характерний напрямок кожної ключової точки, щоб отримати орієнтовано-нормалізовані дескриптори та забезпечити інваріантність до обертання.

Концепція дескриптора BRISK використовує шаблон шляхом аналізу точок, що розташовані рівномірно розподілено по колам, концентричним 3 ключовою точкою. Це забезпечує інтегрований ана- ліз та високу швидкість оброблення чи зберігання. BRIEF-дескриптор тут забезпечує розпізнавання однакових ділянок зображення, знятих з різних точок зору.

Встановлення відповідності двох дескрипторів ORB чи BRISK - це обчислення їх відстані Хемінга: кількість бітів, відмінних у дескрипторах. Відповідні операції зводяться до побітової логічної дії XOR, що обчислюється дуже ефективно [2].

Відзначимо, що модульність побудови методів ORB, BRISK дає можливість вибрати довільний спосіб побудови детектора ОТ у поєднанні з будьяким способом визначення дескриптора й навпаки, оптимізуючи бажану продуктивність вирішуваних задач [1-7].

У BRISK отримана порівняна 3 SIFT та SURF точність для розпізнання зображень, але при цьому досягнута в декілька разів вища швидкодія реалізації [6]. Відзначимо, що на окремих тестових зображеннях точність детектування за допомогою BRISK значно вище, ніж з використанням SURF-дескрипторів.

Таким чином, основні переваги новітніх методів ORB та BRISK полягають у забезпеченні суттєво вищої швидкодії за рахунок спрощення процесу оброблення та побудови і використання дескриптора бінарного типу.

\section{Особливості розроблення програмних засобів}

Програмна реалізація детекторів ORB та BRISK знайшла відображення у сучасних бібліотеках комп'ютерного зору, таких як OpenCV [6, 11,12]. Функції цієї бібліотеки забезпечують:

- зберігання даних зображення;

- визначення ОТ на зображенні або серіях зображень;

- зберігання даних про ключові точки та дескриптори;

- порівняння ОТ та знаходження найкращих відповідностей для кожного дескриптора із набору запитів;

- виведення зображень та даних, отриманих після їх обробки.

Для ORB та BRISK є можливість управління числом виявлених OT. Для ORB на процес виявлення OT впливають показники:

- максимальна кількість збережених ОТ;

- масштабний коефіцієнт поділу піраміди, знаходиться в межах 1...2 та впливає на деталізацію оброблення зображення;

- обмежувач на кількість рівнів піраміди;

- розмір границі навколо вже визначеної ОТ, всередині якої нові ОТ не формуються;

- знайдений поріг для детектора Харіса, що використовується для класифікації і збереження найліпших ОT. 
Обчислення, аналіз та оброблення ОТ нами реалізовано у вигляді програмного засобу на основі модуля features2d до крос-платформної бібліотеки OpenCV 3.4, яку можна використати в операційних системах Windows, Linux, MacOS, Android, iOS. Програмна модель реалізована у вигляді засобу мовою C++ для використання в операційній системі Windows. Формат зображення - .png.

Бібліотека OpenCV написана мовою C++ i популярна за рахунок своєї відкритості та можливості безкоштовно використовуватися в навчальних та комерційних цілях. Також підтримується можливість використання бібліотеки у мовах програмування Python, Java, Ruby, Matlab, Lua та інших. Фактично, OpenCV - це набір типів даних, функцій i класів для обробки зображень алгоритмами комп'ютерного зору $[11,12]$.

Зауважимо важливі для застосувань властивості детекторів ORB та BRISK. Так, метод ORB визначає значніші за розміром масиви OT у порівнянні $з$ SURF, однак, при цьому його дескриптори часто скупчуються і не завжди відображають особливості об'єкту [3].
У BRISK є можливість управління числом ОT. На кількість виявлених ОТ впливають такі показники, як: поріг алгоритму FAST для різниці між інтенсивністю центрального пікселя та пікселями кола навколо нього; номер октави, що встановлює крок стиснення зображення; параметр масштабу для вибору околиці ОТ; радіуси для BRIEF (у пікселях), де взято зразки навколо OT; кількість точок для BRIEF при відборі зразків; мінімальний та максимальний пороги для пар точок при формуванні дескриптора та ін.

Дескриптори мають вид бінарного вектора розміром 256 для ORB та 512 для BRISK. Дескриптори кодуються у Open CV у вигляді типу uchar (unsigned char - тип даних в C++, використовують для зберігання символів, об'єм 8 біт, значення 0..255), а не в бітах. Вони зберігаються в матриці, де кількість рядків дорівнює числу виявлених дескрипторів, а число стовпців дорівнює 32 (256 бітів дескриптора трансформуються у 32 uchar).

Дескриптор ORB (два приклади) має вигляд, зображений на рис. 1, де одиниця позначена чорним кольором, а нуль - білим. Приклади дескриптора BRISK зображені на рис. 2.

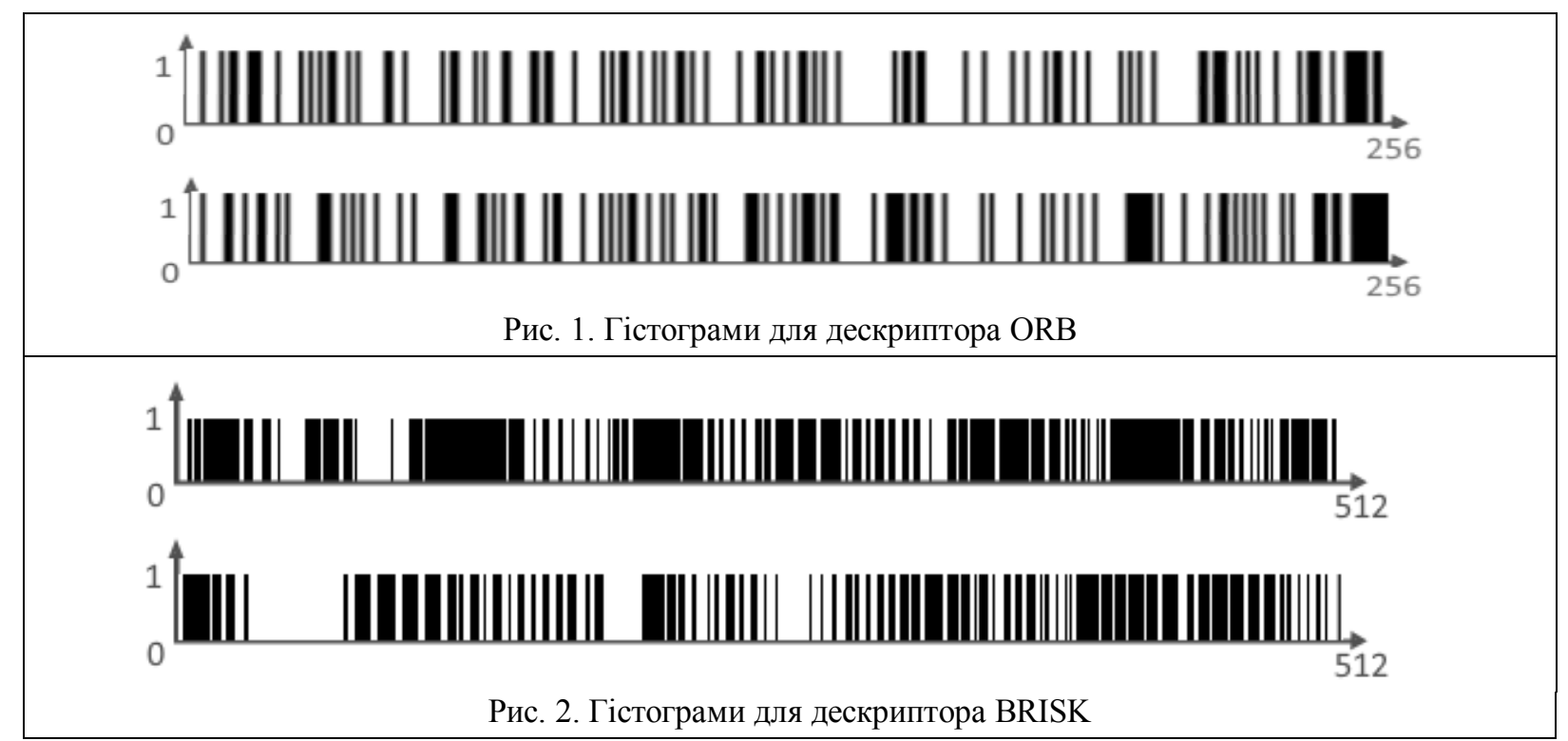

\section{Застосування детекторів ОТ для класифрікації об'єктів}

Розглянемо практичний приклад застосування детекторів ORB, BRISK для класифікації зображень, що містять візуальні об'єкти. На рис. 3 наведено приклади множини координат, отримані детекторами ORB, BRISK.

Нехай задано множину $Z=\left\{Z^{j}\right\}_{j=1}^{J}$ ознак бази зображень, яку складають еталони ( $\mathrm{Z}^{\mathrm{j}}$ - еталон, J число класів). На етапі попередньої обробки множину Z розбиваємо на скінчену кількість $\mathrm{k}$ кластерів $\mathrm{M}=\left\{\mathrm{M}_{\mathrm{i}}\right\}_{\mathrm{i}=1}^{\mathrm{k}}$, так що $\mathrm{M}_{\mathrm{i}} \cap \mathrm{M}_{\mathrm{d}}=\varnothing, \mathrm{Z}=\cup \mathrm{M}_{\mathrm{i}}$,
$\mathrm{M}=\mathrm{Z}$ [3]. Кожний з кластерів $\mathrm{M}_{\mathrm{i}}$ характеризується центром $\mathrm{m}_{\mathrm{i}}$, для бази маємо кортеж центрів $\mathrm{m}=\left\{\mathrm{m}_{\mathrm{i}}\right\}_{\mathrm{i}=1}^{\mathrm{k}}$.

Кластерування здійснює відображення еталонної множини ОТ в себе $\mathrm{Z} \rightarrow \mathrm{Z}$, причому кожна ОT належить одному із кластерів.

Для цього застосуємо онлайн процедуру мережі Кохонена [3]. Нехай задана навчальна множина даних $\mathrm{W}=\left\{\mathrm{x} \mid \mathrm{x} \in \mathrm{R}^{\mathrm{n}}\right\}, \mathrm{W} \subseteq \mathrm{R}^{\mathrm{n}}$, що складає набір дескрипторів ОТ бази еталонів. Тепер побудуємо кортеж $\mathrm{k}$ опорних (модельних) векторів $\mathrm{M}=\left\{\mathrm{m}_{\mathrm{i}}\right\}_{\mathrm{i}=1}^{\mathrm{k}}, \mathrm{m}_{\mathrm{i}} \in \mathrm{R}^{\mathrm{n}}, \mathrm{i}=1, \ldots, \mathrm{k}$. 

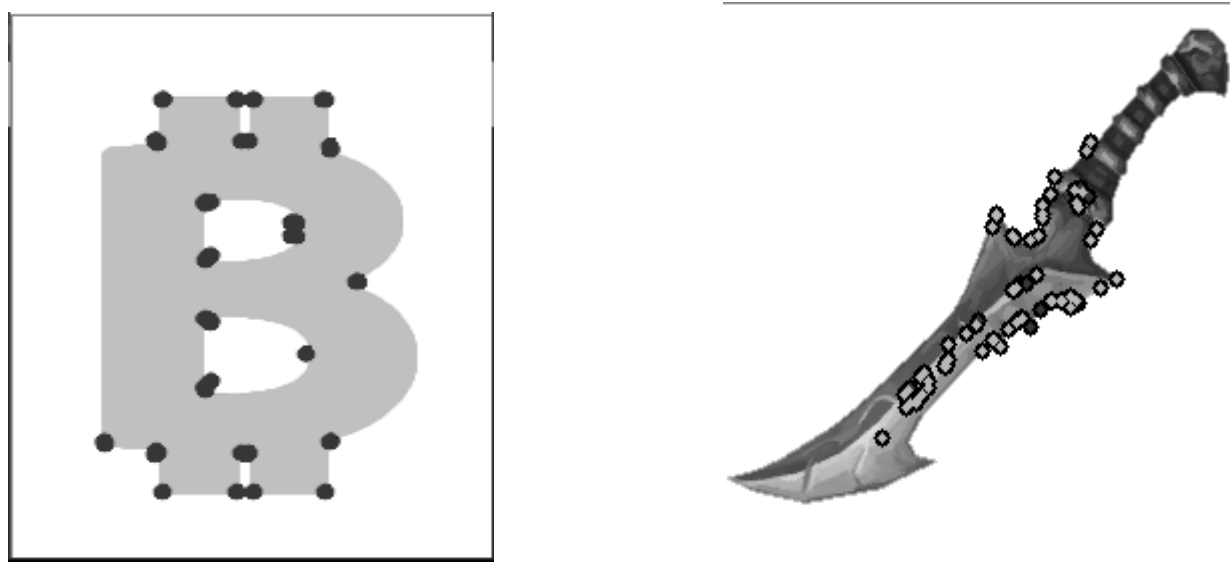

Рис. 3. Зображення координат дескрипторів ORB, BRISK

Для сформованого набору $\mathrm{M}$ апроксимація довільного вектора $\mathrm{x} \in \mathrm{W}$ конкурентним способом означає визначення номера $v$ найближчого до нього (у метриці $\left.\rho\left(\mathrm{x}, \mathrm{m}_{\mathrm{i}}\right)\right)$ вектора $\mathrm{m}_{\mathrm{v}} \in \mathrm{M}$ у просторі модельних векторів:

$$
\mathrm{v}=\arg \min _{\mathrm{i}=1, \ldots, \mathrm{k}} \rho\left(\mathrm{x}, \mathrm{m}_{\mathrm{i}}\right) .
$$

Модель (1) називають конкурентним навчанням Кохонена [1]. Для традиційного варіанту онлайн-навчання, якщо дескриптори ОТ $\mathrm{x}[\mathrm{t}] \in \mathrm{W}$ поступають по черзі, центр $\mathrm{m}_{\mathrm{v}}$ кластера, який став переможцем в (1), на кроці $\mathrm{t}=1,2, \ldots, \mathrm{s}$ навчання коригується у відповідності до виразу

$$
\mathrm{m}_{\mathrm{v}}[\mathrm{t}+1]=\mathrm{m}_{\mathrm{v}}[\mathrm{t}]+\alpha[\mathrm{t}]\left(\mathrm{x}[\mathrm{t}]-\mathrm{m}_{\mathrm{v}}[\mathrm{t}]\right),
$$

де $\mathrm{s}=$ card $\mathrm{W}$ - повний обсяг навчальної вибірки (загальне число ОТ бази зображень), а параметр $\alpha[t]$ задається дослідником та визначає швидкість навчання, причому $\alpha[\mathrm{t}] \rightarrow 0$ при $\mathrm{t} \rightarrow \mathrm{s}$. Існує величезне різноманіття стратегій та технологій навчання (2), включаючи навіть моделювання динаміки топології мережі $[3,10]$.

Якість кластерування оцінюють значенням критерію похибки - усередненої суми квадратів відхилень від центрів сформованих кластерів

$$
\mathrm{E}=\frac{1}{\mathrm{~s}} \sum_{\mathrm{i}=1}^{\mathrm{k}} \sum_{\mathrm{v}=1}^{\mathrm{s}(\mathrm{i})} \rho^{2}\left(\mathrm{x}_{\mathrm{v}}, \mathrm{m}_{\mathrm{i}}\right),
$$

де s(i) - потужність i -го кластера [3].

У випадку, коли число $\mathrm{k}$ кластерів дорівнює числу еталонів бази зображень, кластерування виконує класифікацію на $\mathrm{k}$ класів у просторі $\mathrm{W}$. Множина дескрипторів ОТ, що описує довільний візуальний об'єкт, може бути класифікована як один із еталонів.

Зауважимо, що якість класифікації зображень, як правило, оцінюється іншим критерієм, наприклад, значенням ймовірності правильного розпізнавання об'єктів.
Наряду з класифікацією на підставі мережі Кохонена розглянемо більш простий евристичний підхід бінарного аналізу, суть якого полягає в наступному.

1. Зважаючи на бінарний вид дескрипторів BRISK, для кожного з еталонів $Z^{\mathrm{i}}$ визначимо вектор $\mathrm{m}_{\mathrm{i}}$ центра класу на підставі логічного правила як

$$
\begin{gathered}
\mathrm{m}_{\mathrm{i}}(\mathrm{b})=\left\{\begin{array}{lll}
1, & \text { при } & \sum_{\mathrm{d}=1}^{\mathrm{s}(\mathrm{i})} \mathrm{x}_{\mathrm{d}}(\mathrm{b}) \geq \mathrm{s}(\mathrm{i}) / 2, \\
0, & \text { при } & \sum_{\mathrm{d}=1}^{\mathrm{s}(\mathrm{i})} \mathrm{x}_{\mathrm{d}}(\mathrm{b})<\mathrm{s}(\mathrm{i}) / 2,
\end{array}\right. \\
\mathrm{x}_{\mathrm{d}} \in \mathrm{Z}^{\mathrm{i}}, \quad \mathrm{b}=\overline{1,12},
\end{gathered}
$$

де $\mathrm{x}_{\mathrm{d}}(\mathrm{b})$ - біт 3 номером $\mathrm{b}$ для дескриптора 3 номером d в описі еталона.

Таким чином значення кожного з бітів центру $\mathrm{m}_{\mathrm{i}}$ для $i$-го класу визначається переважною більшістю значень відповідних бітів усіх дескрипторів ОТ, які належать еталону $\mathrm{Z}^{\mathrm{i}}$.

2. Аналізуємо елементи $\mathrm{x} \in \mathrm{Z}$ спільного вмісту структурних описів бази еталонів (навчальна вибірка) шляхом віднесення їх до відповідного класу 3 використанням конкурентного способу (1). Тут у якості $\rho\left(\mathrm{x}, \mathrm{m}_{\mathrm{i}}\right)$ застосуємо метрику Хемінга

$$
\rho\left(\mathrm{x}, \mathrm{m}_{\mathrm{i}}\right)=\sum_{\mathrm{b}=1}^{512}\left|\mathrm{x}(\mathrm{b})-\mathrm{m}_{\mathrm{i}}(\mathrm{b})\right|,
$$

що визначає кількість розбіжних бітів для двох двійкових послідовностей однакової довжини (детекторів ОТ).

У результаті оброблення для кожного еталона отримуємо його кластерне подання $\mathrm{H}\left[\mathrm{Z}^{\mathrm{i}}\right]=\left(\mathrm{h}_{1}^{\mathrm{i}}, \ldots, \mathrm{h}_{\mathrm{J}}^{\mathrm{i}}\right)$, де $\mathrm{h}_{\mathrm{a}}^{\mathrm{i}}$ - цілі числа, яке відповідає розподілу елементів множини $Z^{\mathrm{i}}$ за класами еталонів.

Етап попередньої обробки на базі бінарного аналізу можна вважати різновидом хешування на множині дескрипторів ОТ еталону. Аналогічну обробку можна використати і для аналізу множини ORB-дескрипторів. 


\section{Результати комп'ютерного моделювання}

3 використанням бібліотеки Open CV [11] у середовищі $\mathrm{C}++$ нами розроблено програмну модель для класифікації зображень на підставі структурних описів, сформованих детектором BRISK. У якості бази еталонів застосовано набір із 5 зображень мечів (рис. 3).

Кількість виявлених ОТ в еталонах розміром $256 \times 256$ коливалась у межах $51 \ldots 75$, загальна кількість ОТ бази (обсяг навчальної вибірки) дорівнювала 314. Центрами класів у відповідності до логіки (4) сформовано дескриптори для кожного із еталонів.

Застосовано підхід бінарного оброблення (етап 2), у результаті отримано матрицю розподілу ОТ по класах у вигляді табл. 1.

Таблиця 1

Розподіл ОТ еталонів по класах

\begin{tabular}{|l|l|l|l|l|l|}
\hline \multirow{2}{*}{ Еталони } & \multicolumn{4}{|l|}{ Класи / Кластери } \\
\cline { 2 - 6 } & $\mathrm{M}_{1}$ & $\mathrm{M}_{2}$ & $\mathrm{M}_{3}$ & $\mathrm{M}_{4}$ & $\mathrm{M}_{5}$ \\
\hline $\mathrm{Z}^{1}$ & 35 & 1 & 5 & 10 & 9 \\
\hline $\mathrm{Z}^{2}$ & 9 & 36 & 6 & 0 & 6 \\
\hline $\mathrm{Z}^{3}$ & 10 & 10 & 27 & 3 & 1 \\
\hline $\mathrm{Z}^{4}$ & 11 & 1 & 6 & 41 & 16 \\
\hline $\mathrm{Z}^{5}$ & 8 & 2 & 2 & 20 & 39 \\
\hline
\end{tabular}

Як можна побачити із табл. 1, множина дескрипторів BRISK для даної бази зображень 3 використанням бінарного оброблення однозначно класифікує множину ОТ кожного $з$ еталонів, так як в таблиці кількість ОТ, віднесених до певного класу максимальна. Помилка (3) нами обчислювалась у варіанті

$$
\mathrm{E}_{1}=\frac{1}{\mathrm{sN}} \sum_{\mathrm{i}=1}^{\mathrm{k}} \sum_{\mathrm{v}=1}^{\mathrm{s}(\mathrm{i})} \rho\left(\mathrm{x}_{\mathrm{v}}, \mathrm{m}_{\mathrm{i}}\right),
$$

де $\mathrm{N}$ - розмір дескриптора (512 чи 256 ), а замість квадрата метрики вибрано іï значення для спрощення та приведення до інтервалу 0...1. Похибка (6) при цьому склала $\mathrm{E}_{1}=0,26$.

Із табл. 1 бачимо також суттєве перевищення максимуму у рядку над найближчим максимумом: більше, ніж удвічі, що гарантує упевнене безпомилкове розпізнавання при віднесенні кожного $з$ дескрипторів окремо у відповідності з конкурентним правилом.

При вирівнюванні числа ОТ в еталонах до величини 51 (усього 255 ОТ) шляхом відкидання точок, координати яких знаходяться поряд у структу- рному описі, отримано аналогічний результат, похибка (6) склала $\mathrm{E}_{1}=0,28$.

Як бачимо, похибка трохи виросла зі зменшенням числа ОТ при описові ідентичного набору еталонних об'єктів. Однак, якість класифікації при цьому збережена. Для порівняння 3 табл. 1 у останньому рядку таблиці отримано значення: 9, 2, 2, 12, 26, що підтверджує впевнену класифікацію, так як максимальний елемент відповідає зразку та у 2,2 рази перевищує найближчий із локальних максимумів. Загалом треба сказати, що детектор BRISK за рахунок суттєво інформативного значення розміру дескриптора, що дорівнює 512, гарантує досить детальне подання і можливість аналізу властивостей зображення з метою результативного розрізнення візуальних об'єктів.

Тепер виконаємо кластерування на конкретній множині дескрипторів для бази із 5 зображень еталонів (рис. 3), взявши за початкові центри по одному дескриптору із кожного еталону. Класифікація на 5 класів реалізована з використанням мережі Кохонена у варіанті, коли на кожному етапі навчання (2) модифікувався лише нейрон-переможець, при значенні $\alpha[\mathrm{t}]=1 / \mathrm{t}$.

Мережа Кохонена дала порівняні результати відносно величини похибки $\mathrm{E}_{1}=0,28$, але спостерігалося дещо менший рівень перевищення максимального елемента над найближчим максимумом (до значення 0,6). Це говорить про необхідність застосування мір подібності інтегрального типу, що забезпечують надійне розпізнавання в цих умовах $[3,7]$.

Подальшого підвищення результативності мережі Кохонена можна досягти також застосуванням пакетного оброблення, так як база ОТ задана. Загалом мережа Кохонена має значно більше можливостей для адаптації до довільних наборів вхідних даних.

За результатами наших експериментів можна сказати, що обробка зображення детектором ORB виконується дещо швидше за BRISK, що дає перевагу при застосуванні ORB для задач реального часу.

$\mathrm{y}$ той же час BRISK формує значно більше число ОТ та аналізує зображення детальніше, що загалом забезпечує його суттєвішу точність щодо розрізнення об’єктів.

\section{Висновки}

У проведеному дослідженні з використанням апарату кластеризації вирішена задача класифікації зображень на базі структурного опису у вигляді множини особливих точок, що визначаються новітніми детекторами ORB, BRISK. Для цього проаналізовано особливості цих детекторів як бінарних век- 
торів, запропоновано способи визначення центрів кластерів шляхом побітового логічного оброблення та порівняння детекторів на основі метрики Хемінга для обчислення багатократних відстаней між дескрипторами замість більш складних метрик. Розроблений метод забезпечує достатній рівень класифікації зображень, що підтвердили наведені результати моделювання.

Наукова новизна дослідження полягає у синтезі нового продуктивного методу структурного розпізнавання зображень на підставі бітового оброблення і побудови класифікаційних рішень у просторі кластер-еталон.

Практична значущість роботи - отримання прикладних програмних моделей для застосування та оцінювання ефективності методів структурного розпізнавання і підтвердження їх результативності в конкретних прикладах базах зображень.

Зважаючи на бінарний вид дескрипторів ORB та BRISK, перспективною можливість побудови результативних правил класифікації, скориставшись механізмами дерев рішення чи хешування.

\section{Список літератури}

1. Ethan Rublee, Vincent Rabaud, Kurt Konolige, Gary Bradski. ORB: an efficient alternative to SIFT or SURF. Computer Vision (ICCV), IEEE International Conference on IEEE, pp. 2564 - 2571, 2011.

2. Stefan Leutenegger, Margarita Chli, Roland Y. Siegwart. BRISK: Binary Robust Invariant Scalable Keypoints. Computer Vision (ICCV), pp. 2548-2555, 2011.

3. Гороховатский В.А. Исследование результативности структурных методов классификации изображений с применением кластерной модели данных / В.А. Гороховатский, Е.П. Путятин, В.С. Столяров // Рaдиоэлектроника, информатика, управление. - 2017. №3 (42). - C. 78-85.
4. Rosten, Edward, Tom Drummond. Machine learning for high-speed corner detection. - 9th European Conference on Computer Vision (ECCV), pp. 430 - 443, 2006.

5. Michael Calonder, Vincent Lepetit, Christoph Strecha, Pascal Fua. BRIEF:Binary Robust Independent Elementary Features. - 11th European Conference on Computer Vision (ECCV), pp. $778-792,2010$.

6. Патин М. В. Сравнительный анализ методов поиска особых точек и дескрипторов при группировке изображений по схожему содержанию [Электронный ресурс] / М. В. Патин, Д. В. Коробов // Молодой ученый. 2016. - №11. - С. 214-221. - Режим доступа: https://moluch.ru/archive/115/31188/.

7. Gorokhovatsky V.A. Intellectual Data Processing and Self-Organization of Structural Features at Recognition of Visual Objects / V.A. Gorokhovatsky, A. V. Gorokhovatsky, A.Ye. Berestovsky // Telecommunications and Radio Engineering. - 2016, Vol. 75, No 2. - P. 155-168.

8. Lowe, David G. Object recognition from local scaleinvariant features. - Proceedings of the International Conference on Computer Vision, pp. 1150 - 1157, 1999.

9. Herbert Bay, Tinne Tuytelaars, Luc Van Gool. SURF: Speeded Up Robust

Features. - Proceedings of the ninth European Conference on Computer Vision, pp. 404-417, 2006.

10. Борисов Е.С. Кластеризатор на основе нейронной сети Кохонена. [Электронный ресурс]. - Режим досmyna: $\quad$ http://mechanoid.kiev.ua/neural-net-kohonenclusterization.html

11. Кручинин А. Распознавание с использованием OpenCV . - [Электронный ресурс]. 2011. - Режими досmyna: http://recog.ru/library/opencv/opencvkruchinin.pdf, свободный. - Загл. с экрана.

12. OpenCV Open Source Computer Vision. [Электронный ресурс]. - Режим доступа:

https://docs.opencv.org/master/index.html, _вободный. Загл. с экрана.

Надійшла до редколегії 10.01.2018

Рецензент: д-р техн. наук, проф. Є.П. Путятін, Харківський національний університет радіоелектроніки, Харків.

\section{АНАЛИЗ СВОЙСТВ, ХАРАКТЕРИСТИК И РЕЗУЛЬТАТОВ ПРИМЕНЕНИЯ НОВЕЙШИХ ДЕТЕКТОРОВ ДЛЯ ОПРЕДЕЛЕНИЯ ОСОБЫХ ТОЧЕК ИЗОБРАЖЕНИЯ}

В.А. Гороховатский, Д.В. Пупченко, К.Г. Солодченко

Решается задача инвариантного распознавания визуальных объектов с использованием структурных методов на основе описаний в виде множества особых точек изображения. Проведен анализ характеристик и средств программного моделирования современных методов ORB и BRISK для определения особых точек. Предложен метод бинарного анализа для формирования центров классов и последующей классификации. Проведено программное моделирование метода в сравнении с сетью Кохонена, получено подтверждение результативности разработанного метода для прикладной базы изображений.

Ключевые слова: компьютерное зрение, структурное распознавание, особые точки изображения, методы ORB, BRISK, метод бинарного анализа, сеть Кохонена, база изображений, программное моделирование, результативность классификациии.

\section{ANALYSIS OF PROPERTIES, CHARACTERISTICS AND RESULTS OF THE USE OF ADVANCED DETECTORS TO DETERMINE THE SPECIFIC POINTS OF THE IMAGE}

V.O. Gorokhovatsky, D.V. Pupchenko, K.G. Solodchenko

The problem being solved is of invariant recognition of visual objects with the use of structural methods based on descriptions in the form of a set of special points of the image. The analysis of the characteristics and means of software modeling of modern methods ORB and BRISK for the determination of special points has been carried out. A method of binary analysis for the formation of the class centers and the subsequent classification is proposed. The program modeling of the method was compared with the Kohonen network, and the results of the developed method for the applied database of images were obtained.

Keywords: computer vision, structural recognition, special image points, ORB, BRISK methods, binary analysis method, Kohonen network, image database, software modeling, classification efficiency. 